\title{
UNIVERSITYOF
}

FORWARD

THINKING

WESTMINSTER用

WestminsterResearch

http://www.westminster.ac.uk/westminsterresearch

Sexualisation, or the queer feminist provocations of Miley Cyrus

McNicholas Smith, K.

This is a copy of the accepted author manuscript of the following article: McNicholas

Smith, K. (2017) Sexualisation, or the queer feminist provocations of Miley Cyrus. Feminist Theory. 18 (3), pp. 281-298. doi:10.1177/1464700117721880. The final definitive version is available from the publisher Sage at:

https://dx.doi.org/10.1177/1464700117721880

(c) The Author(s) 2017

The WestminsterResearch online digital archive at the University of Westminster aims to make the research output of the University available to a wider audience. Copyright and Moral Rights remain with the authors and/or copyright owners.

Whilst further distribution of specific materials from within this archive is forbidden, you may freely distribute the URL of WestminsterResearch: ((http://westminsterresearch.wmin.ac.uk/)).

In case of abuse or copyright appearing without permission e-mail repository@westminster.ac.uk 


\section{Sexualisation, or the queer feminist provocations of Miley Cyrus}

Dr Kate McNicholas Smith

Department of Sociology, Lancaster University 


\begin{abstract}
Miley Cyrus has increasingly occupied debates at the centre of feminist engagements with popular culture. Evoking concerns around young women and 'sexualisation', Cyrus emerges as a convergent signifier of sexualised media content and the girl-at-risk. As Cyrus is repeatedly invoked in these debates, she comes to function as the bad object of young femininity. Arguing, however, that Cyrus troubles the sexualisation thesis in the provocations of her creative practice, I suggest that this contested media figure exceeds the frames through which she is read. Thus, I ask: what kinds of insights might be possible if we were to transform the terms on which we approach this figure? Considering a selection of the images and performances that constitute the Cyrus archive, this paper proposes a reading of Cyrus as performative provocation. Mobilising an existing sensibility of queer feminist struggle, Cyrus emerges as disruptive, albeit contradictory, figure. Questions of privilege and limit as well as possibly emerge in this discussion, as well as questions over what constitutes feminist struggle.
\end{abstract}

\title{
Keywords
}

Sexualisation; Miley Cyrus; popular culture; feminist; queer; performance; femininity; drag 


\section{Sexualisation, or the queer feminist provocations of Miley Cyrus Introduction: making sense of Miley Cyrus}

On stage, a model of a giant teddy bear, electric panel for eyes matching the flashing lights on the boots the bear is wearing, opens from the stomach to reveal a set of steps. Lit by green and blue lights, the scene is accompanied by the sound of a beating drum and the swell of music from the musicians on stage. Performers dressed in white bear costumes, various expressions fixed in cartoonlike illustrated faces, one arm raised in a constant wave, turn to look as a figure appears at the top of the stairs. Dressed in a silver corseted leotard embellished with a bear face, her hair is shaved at the sides with the rest pulled into two tight buns on the top of her head, her lips made up in a dark red lipstick. To the sound of the crowd's applause, the figure, a young white woman, pauses to stand with one leg raised against the side of the bear, leaning back in a pose that evokes conventions of representations of women's bodies.

Descending the stairs, the woman moves in an exaggerated manner, contorting her face into a series of expressions; posing with her tongue out of the side of her mouth, she leans back, eyes closed and smiling, she bares her teeth at the camera and pouts seductively. As she moves, she mimes twisting long hair in her hands, before throwing her hand up, as if to throw the hair off, and moving to the centre of the stage. Here, she is surrounded by a line of dancing bears and four dancers, all women of colour, carrying oversized teddy bears on their backs. One carries a basket of marshmallows in gift bags, each packet decorated with the face of a dog and the name 'Floyd'. The group follow a loose choreography, lined up along the stage until the music builds and the bears part to leave the woman, shouting to the crowd to 'make some noise', and the dancers centre stage. They dance together until the music fades. The woman poses, mouth open, tongue out, one arm raised to point to the audience and the other to her crotch.

This is the introduction to pop performer Miley Cyrus' now infamous 2013 performance at MTV's video music awards ceremony (VMAs). The ceremony, launched by music and popular culture 
based cable channel MTV in 1984, celebrates the visual medium of the music video. Offering awards such as 'video of the year', best direction', 'best choreography' and 'best visual effects', the conventions of the VMAs encourage the spectacular. They have been, over the years, host to a number of highly publicised performances (from Madonna and Brittany Spears' 2003 kiss and Lady Gaga's 2010 meat dress, to Nirvana's 1992 performance of 'Lithium'). As Cyrus describes: 'every VMA performance, that's what you're looking for; you're wanting to make history' (in Montgomery, 2013). In 2013, Cyrus followed this entrance with a performance of her hit pop/r\&b single 'We Can't Stop' (RCA Records 2013). The song's lyrics describe partying and recreational drug use, and arguably evoke the paradoxical tensions of postfeminist discourses of 'choice' and sexual freedoms:

It's our party, we can do what we want

It's our party, we can say what we want

It's our party, we can love who we want,

We can kiss who we want

We can live how we want (Williams II et al, 2013)

Accompanied by the dancers described above, Cyrus showcased the single at the VMAs in a performance particularly noted for its use of the dance move 'twerking'; an appropriative performance that many argued 'masked the black communal roots of the social dance from New Orleans' (Gaunt, 2015: 244). Cyrus' use of women of colour as backing dancers - most notably burlesque dancer Amazon Ashley - in a routine which involved her performing smacking the women's backsides and twerking up against them garnered critiques of cultural appropriation, the use of 'ethnic marker[s] to transform her brand identity' (Gaunt, 2015: 245) and a sexualised racialisation. Cyrus subsequently performed a duet with singer, songwriter and producer Robin Thicke. Thicke's 'Blurred Lines' was already a controversial choice: with lyrics such as 'you know you want it' and the blurred lines of the title, the visual imagery of the video is described by Thicke himself as 'completely derogatory towards women', stating: 'what a pleasure it is to degrade a woman' (in Phili, 2013). The song, as Tanya Horeck describes, has been 
'castigated as a "rape anthem" and banned from several university campuses in the UK' (2014: 1106). Cyrus' and Thicke's collaboration was, however, made most controversial by the style of the performance itself. Cyrus, dressed now in a beige pvc bikini, danced and 'twerked' around Thicke, repeatedly rubbing a foam finger against his crotch. How can we make sense of this representation of young female sexuality and its contradictory convergences of gender, race, sexuality and power? Furthermore, what is at stake in this sense-making? As discourses of sexual freedom, sexualisation, rape culture and racialisation circulate around Cyrus, longstanding tensions around the politics, possibilities and privileges of disruptive femininity (and feminism) are evoked. With these questions in mind, I ask: what kind of provocations is Miley Cyrus offering us and how might we understand them?

As Kerry Griffiths describes, 'the transformation of American actress and singer Miley Cyrus' image from girl next door, child star of children's television series Hannah Montana, into being increasingly known for her raunchy and provocative stage performances, has not gone unnoticed' (2015: 20). On the contrary, Cyrus has become 'the subject of widespread media attention and scrutiny' (Griffiths, 2015: 20). Under this scrutiny, this media figure and her provocative mediation of gender, race and sexuality are made subject to a sense making imperative that, I argue, reduces this debate to one dominant frame of analysis. As Cyrus' increasingly explicit media presence is discussed in multiple news reports, think pieces, online discussions and TV debates, a dominant reading emerges of the sexualisation thesis. Emerging from various quarters, the phrase 'sexualisation of culture', as Rosalind Gill describes, 'is used to capture the growing sense of Western societies as saturated by sexual representations and discourses' and the spread of pornographic imagery into popular culture (2012: 484). Notably, as exDisney child star, Cyrus occupies a dual position of sexualised star and 'at risk girl' (Harris, 2004); symbolising both threat and victim of the so-called sexualisation of culture. 
If "discursive struggles over the meanings of feminism are... staged in and through media culture' (Hamad and Taylor, 2015: 126), so too in the frames of feminist critique through which they are understood. To a certain extent, the Miley Cyrus/sexualisation debate works to draw attention to the limits and tensions of female subjectivity in public cultures; continuing a series of critical conversations around gender, sexuality, racialisation and a profit driven music industry. However, as I will argue in this paper, it might also obscure the possibilities of popular culture as a site of struggle; limiting our approach to forms of feminist media content and engagement. Meanwhile, Cyrus's provocative use of the body, her various incarnations, collaborations and media biography, do not make for a stable narrative around these debates. Rather, I suggest, Cyrus's media presence exceeds the terms of the sexualisation debate, making visible a more complex convergence of gender, sexuality and embodiment than this discussion allows for. Although there are critical limits to these performances that require continued analysis, in this paper I want to turn centrally to the possibilities that might be opened up by further explorations of the visual imagery and cultural references of Cyrus' performances. Considering a selection of examples of Cyrus' media content from the 2013 VMA awards onwards, I ask in this article: what might be gained from approaching Cyrus on different terms? Beginning with a discussion of the framing of Cyrus within the sexualisation debate, I consider the implications and limits of this analysis; arguing that it risks fixing Cyrus as bad object. Positing Cyrus as disruptively in excess of this debate, I turn to a consideration of Cyrus and/as performance. Drawing out the queer/feminist influences and provocations of the Cyrus media archive, a more disruptive account of gender and sexuality emerges. Thus, I propose in this paper a series of reflections that find queer feminist possibilities in Miley Cyrus, with the aim of extending the discussion of her media presence to consider the multiplicities of this media figure and the forms of visibility and attachment she might make possible, as well as those she might block. ${ }^{\mathrm{i}}$ Drawing attention to the spectacular excesses of her visual aesthetics, her public identifications with queer cultures and her 
experimental mobilisations on transmedia platforms, I ask whether Cyrus might thus emerge as an unstable but nonetheless disruptive figure of young femininity in popular culture.

\section{The sexualisation of culture debate}

As has been well documented, “"[s]exualisation” has come to be regarded in Britain as a significant social problem' (Duschinsky, 2013: 137). From politicians to think tanks to feminist theory, the discussion has emerged in various formulations. Feona Atwood and Clarissa Smith describe the sexualisation debates as emerging 'both as part of a tradition of suspicion - of media technologies, sex, and young people - and as part of a series of responses to real changes in the significance of sex in contemporary western societies' (2011: 235). In his genealogy of the term, Robbie Duschinsky describes its initial use in "feminist discourses... which problematised "sexualisation" as media representations distorted by commercialisation, sexism, and an ideological backlash against the gains made by feminism' (2013: 137). Feminist academics and activists Gail Dines and Julia Long, for example, have written of the 'pornification' of contemporary society, opposing 'sexualised images of women' that, they argue, 'perpetuate myths of women's unconditional sexual availability and object status, and thus undermine women's rights to sexual autonomy, physical safety and economic and social equality' (2011). Others have considered sexualisation as an element of a postfeminist sensibility (Gill, 2007; Jackson \& Vares, 2011; Gill \& Scharff, 2011). As Duschinsky outlines, the term has also 'been increasingly utilised in media discourse' (2013: 258), emerging in a series of popular books (Levy, 2005; Durham, 2008; Tankard Reist, 2009; Paul, 2005) and countless news media, largely mobilising 'a narrative that suggests that sexist cultural representations have been undermining the confidence and social power of young girls, and putting them at sexual risk by blurring the crucial line between "normal" women and the "unhealthy" lifestyle of strippers or prostitutes' (Duschinsky, 2013: 258). If such critiques draw (albeit problematically) on feminist critique, the term has also been taken up in more explicitly conservative 
ways; 'co-opted' as Duschinsky describes, 'by right-wing discourses' (2012: 15). In the UK, the build up to the general election in 2010 saw David Cameron as leader of the Conservative Party evoke 'sexualisation' in the context of a conservative discourse of family values and childhood innocence. Cameron's critique of what he described as 'unnecessary and inappropriate commercialisation and sexualisation' (The Telegraph, 2010) became a significant feature in his election campaign, and, following the election of a coalition government of the Conservative and Liberal Democrat Party, then prime minister Cameron commissioned the much debated 'Letting Children be Children' review, undertaken by Reg Bailey for the Department of Education (2011). The review's account mobilises the 'crisis' of sexualisation 'as a problem not of sexism, but primarily of public decency' (Duschinsky, 2013: 260).

As Gill argues, the sexualisation thesis mobilises a particular "privileged object of anxiety and 'concern"” in the figure of 'the White, western, middle class, girl-child' (2012: 741). Thus, as Sue Jackson and Sarah Goddard describe, the 'sexualised' girl' has come to constitute a contemporary 'girl crisis' (2015: 241). The conflation of girls and young women here means that, as Meg John Barker and Duschinsky argue, 'young women are situated as children, their sexuality and desire rendered pathological and morally unacceptable as judged by a conservative standard of decency' (2012: 305). The symbolic girl child also homogenises differences between girls and women themselves. Yet, as Gill has argued, “sexualisation' is far from being a singular or homogenous process... different people are 'sexualised' in different ways and with different meanings - and indeed many remain excluded' (2009: $138)$. 


\section{'No matter what, I'm the bad girl'ii: Cyrus, sexualisation and the bad role model}

In an article in The Guardian newspaper in 2013, journalist Michael Hann reflected that exDisney star Cyrus 'evidently wants to cast aside her crown as queen of the tweens, and she's gone about it in the way that many young women who became famous very young have done: she's embraced sexualisation' (2013). In October 2013 British newspaper The Telegraph reported that "“sexualised" popstars are more of a threat to children on the internet than hardcore pornography' (Graham, 2013); Cyrus was cited as a central example of this threat, and an image of her from her from her VMA awards performance - bending over, the picture taken from behind - accompanied the text. Such readings of Cyrus have dominated the press post-VMA performance. As Jackson, Goddard and Sophie Cossens note, 'a unifying concern about the effect of Cyrus' hypersexualised performances on the young girls who have long comprised her main audience' (2016: 2) continues to dominate. In August 2015, the results of a poll of British parents on voucher site, Vouchercloud, declaring Cyrus the worst 'celebrity role model' (Morgan, 2015) were circulated in the British press. In a personification of the risk of sexualisation, Cyrus emerges as both victim and perpetrator; her audience of young female fans further signifying girls at risk. In this repeated circulation, Cyrus comes to function not only as an example, but the ultimate bad object of the sexualisation debate.

The imagined girl at the centre of these debates assumes 'a simple media-effects model that positions girls as uncritical media victims' (Jackson \& Vares, 2011: 135). Emphasising, as Emma Renold and Jessica Ringrose suggest, 'the harmful effects of media exposure with little analysis of how girls themselves negotiate the media in their everyday lives' (2011: 391). Research with girls themselves suggest more complex processes of media engagement. As Tiina Vares and Sue Jackson describe: 'through our analysis of girls' talk about Miley Cyrus, we suggest that the framing of female celebrities as 'sexualising agents' is overly deterministic and ignores the complexities and nuances of girls' 
engagement with popular celebrities' (2015: 256). Similarly, Jackson, Goddard and Cossens explore the 'variability of sense-making' (2016: 2) Cyrus' audience employ, exploring her function as 'a boundary maker around which cultural norms of femininity were constructed and negotiated' (2016: 14). Even in these accounts however, Cyrus can come to function as bad object, evidence largely only of girls' ability to critically navigate sexualised media content. As Cyrus herself articulates: 'I'm the bad girl for growing up, I'm the bad girl for living my dreams, No matter what, I'm the bad girl' (Cyrus, 2011).

\section{'I don't relate to being boy or girl, and I don't have to have my partner relate to boy or girl':}

\section{Cyrus' queer visibility}

If Cyrus comes to signify 'the spectacular figure of the premature or overly (hetero)sexualised girl child' (Epstein , Kehily \& Renold, 2012: 251), this is complicated by her mobilisation of queer subjectivity. In 2014, Cyrus won the VMA award for 'Video of the Year' for her controversial video for hit single, 'Wrecking Ball'. Rather than go onstage to collect the award herself, Cyrus sent her date for the evening, Jesse Helt. Helt stated he was accepting the award on behalf of the '1.6 million runaways and homeless youth in the united states, who are starving lost and scared for their lives right now. I know this because I am one of these people'. Cyrus then launched a fundraising campaign for the youth homelessness organisation My Friends Place, using her Facebook page, website and online fundraising platform Prizeo. In 2015 Cyrus launched the Happy Hippie foundation, a non-profit organisation challenging 'injustice facing homeless youth, LGBTQ youth and other vulnerable populations' (The Happy Hippie Foundation, 2015). The foundation was partnered with Facebook, using the social media site to raise money and circulate materials. ${ }^{\text {iii }}$ A central element of Cyrus's collaboration with the foundation was the launch of the campaign \#InstaPride with photo sharing social media platform Instagram. Cyrus' Instagram platform was used to publish photographs and life stories of people who identify as genderqueer, gender non-conforming, agender and transgender. In an interview with Out Magazine in May 2015, Cyrus described her own struggles with the limits of gender identity, and in 
particular the norms of femininity through which she has been so powerfully defined: 'I don't relate to what people would say defines a girl or a boy', noting that 'being a girl isn't what I hate, it's the box that I get put into' (in Krochmal, 2015). In an interview with Paper magazine a month later, Cyrus described a fluid sense of gender and sexuality, further mobilising herself as public queer figure: 'I don't relate to being boy or girl, and I don't have to have my partner relate to boy or girl' (in Petrusich, 2015). Stating that she has had romantic relationships with women in the past that have simply gone unrecognised by the press, Cyrus articulates a recognisable coming out narrative: Aged fourteen, 'I remember telling [her mother] I admire women in a different way. And she asked me what that meant. And I said, I love them. I love them like I love boys... it was so hard for her to understand... I just asked for her to accept me. And she has' (in Petrusich 2015). In an Elle magazine article later that year she described herself as identifying as pansexual (De Casparis, 2015). In these ways, Cyrus radically disrupts the heteronormative discourses of sexualisation. In the context of what Renold describes as "the paradoxical possibilities of "doing girl” within a nexus of competing and contradictory discourses of presumed innocence and normative (hetero)sexuality' (2008: 131), Cyrus opens up frames for imagining alternative possibilities of intimacy and desire. Whilst Cyrus' articulations of queer desires and identifications might evoke a contemporary 're-making of sexual kinds' that includes what Lisa Backman describes as the 'heteroflexible' - 'an invitation to straight men and women to open themselves to the possibility of emotional and sexual samesex relationships' (2009: 124) - the extent of this project seems to exceed the more familiar trope of temporary queerness. Certainly, the images and narratives of Cyrus' extended media archive make visible a queer set of identifications and attachments, and, critically, articulate some of the material limits and violences of heterosexist social worlds. 


\section{'It's sexual—it is. But in a different way': Cyrus' excessive femininity}

Like many contemporary celebrities, Cyrus' media platform extends beyond the conventional media forms for which she is most known (television, film and music) and into social media. Alongside the \#Instapride series, Cyrus' Instagram hosts a series of often psychedelic, distorted and heavily manipulated images, as well as regular nudity and marijuana smoking. Old images of Cyrus are superimposed onto other images (such as Cyrus as a child sitting on Elvis' lap, climbing out of Paris Hilton's mouth, and teenage Cyrus climbing out of a giant eye) or manipulated (such as a Cyrus as a child smoking marijuana, wearing a sequined eye patch). Images of pop culture figures are repeated throughout, in particular Elvis Presley, Dolly Parton (Cyrus' godmother), Justin Bieber, Kanye West and Kim Kardashian. In the repetition and layering of this imagery, there is a kind of celebration and disturbance of celebrity and stardom. The images evoke fandom and attachment, play on the romantic and the familial, trouble authenticity and discomfort in their surreal juxtapositions; in particular in the use of images of Cyrus the child star. As Debra Ferreday suggests in her discussion of the bare faced selfie, 'women's self-created images and the practices through which they are produced' tend to be considered 'unworthy of engagement or analysis' (2014: 143). Similarly, such media content tends to remain absent from discussions of Cyrus' media presence.

If, as Gill describes, 'one of the most striking aspects of postfeminist media culture is its obsessive preoccupation with the body' (2007: 149), Cyrus makes that preoccupation almost uncomfortably visible. A constant theme of Cyrus' Instagram, alongside regular nudity, the body appears in repeated manipulations in which eyes and mouths are superimposed onto other shots, producing distorted images in which Cyrus' eyes are replaced by lips, additional eyes appear mid forehead and so on. In this series of images there is an unapologetically embodied display of the social markers of female sexuality. As Cyrus has posited when questioned on her use of the body in interviews and on talk shows: 
'I'm using it as a power stance' (in Steinmetz, 2015). If the topless woman is a familiar convention of heterosexist media, Cyrus is topless to excess. If body parts are coded with sexual availability, Cyrus makes mouths, tongues and genitals confrontational in their hypervisibility. In her account of the postfeminist sensibility of Hannah Montana, Morgan Genevieve Blue argues that 'each girl or character [thus Montana and Cyrus] can be understood as having chosen to perform a femininity that finds its locus in the maintenance and control of the body' (2013: 661). In her contemporary media formation, post-Montana Cyrus mobilises a chaotic disruption of this regulatory control. Cyrus' is an excessive embodiment, and as Hannah McCann argues, 'excessive femininity is troubling because it blurs boundaries, is unruly and difficult to contain' (2015: 249). As Cyrus articulates: 'I'm not really trying to be sexy. I try to explain to girls that you don't have to have long blond hair and big boobs. It's sexual—it is. But in a different way' (in Gevinson, 2014).

\section{'These aren't my real tits': Cyrus' pop femininity drag}

In 2015, Cyrus returned to the VMAs as host. Prior to the awards Cyrus described her vision for the show in an interview with The New York Times: 'What I'm trying to do is create my Instagram which people love to think is so freaky - in real life. It's letting people into my world' (in Coscarelli, 2015). Prior to the awards, promotional materials were released of digital artwork, animations and imagery, created by artist Jen Stark. A hand painted image of dripping waves of psychedelic colour behind an image of Cyrus licking a VMA award was showcased in LA, and teaser videos of Cyrus floating through a multicoloured kaleidoscope wormhole circulated online. Stark and director and animation artist David Lewandowski created further animations for the show, including introductory visuals of Stark's animated images, footage from past awards, animations and glitch art, accompanied by a distorted voice over. In what is both continuity and departure from her 2013 performance, Cyrus as 
VMA host offers a sophisticated transmedia spectacle; chaotic and uncontained, its carnivalesque excesses revealing the performativity of gender, sexuality and stardom.

Cyrus closed the 2015 VMA awards with another highly publicised performance, this time of new single 'Dooo It!' (Smiley Miley Inc. 2015). To introduce her final appearance, stars of the \#Instapride series gathered onstage, their introductory speech recalling the continued debate over Cyrus' influence: 'The truth is, tonight does matter. Why? Because of all the sticky, young impressionable minds of our future who are watching us right now' (VMAs, 2015). In this framing, Cyrus is reclaimed from the position of bad role model, her performances contextualised through the politics of queer visibility. A dark stage is suddenly lit by a full size screen showing a close up of a woman's mouth, breathing out smoke. A door opens in the screen and Cyrus enters. Cyrus on the stage and Cyrus on screen begin the opening lines of the track: 'Yeah I smoke pot, yeah I love peace'. The mouth on screen cuts to the same shot but this time the mouth is covered in a glittery slime. In an outfit that suggests the distortions of the Instagram imagery brought to life, Cyrus wears a skin tight, glittered, multicoloured legging on one leg, gold pants and braces: one strap featuring an eye covering her breast and the other a sideways mouth tongue hanging out, and one purple sequined sleeve. The screen shows a series of close ups and reverse motion shots of Cyrus: the glittery slime pouring down her face, being rubbed across, in and out of her mouth. Onstage, the lighting lifts to show psychedelic alternative rock band The Flaming Lips, whom Cyrus worked with on the song and the album that she would release free to stream on her website that same day. As Cyrus walks to the front of the stage, others emerge onstage to join her: a group of thirty drag queens, burlesque performers (including Amazon Ashley), queer performers (gay dance act Barbie’s Addiction), and transgender models, performers and activists (such as Carmen Carrera). Notably, almost all of the twenty six drag performers on stage had appeared previously on reality TV show Ru Paul's Drag Race: shown on Logo TV, 'stitching together the fashion, performance and competition of hit series 
like Project Runway, American Idol and Survivor the TV show Drag Race is a "trans"lation of sorts, a knowing parade of gender crossing celebration, ... a queer spectacle' (Poulson-Bryant, 2013: 218). Their appearance here is thus multiply coded in both queer and celebrity culture, and playfully evokes the themes of artifice, performance and un/reality that infuse the Instagram collages.

Like Cyrus, the performers' costumes are brightly coloured, tightly fitted, composed of and patterned with eyes and mouths. The costumes were designed by queer fashion designer BCALLA in collaboration with Cyrus and her stylist Simone Harouche. BCALLA is known for futuristic, unisex, skin tight clothing with influences from drag and s\&m, making its appearance here particularly significant: 'BCALLA, known for supplying tight bodied club kids and drag queen with the equally tight vinyl they crave, is all about showmanship' (Mohammed, 2015). Designer Brad Callahan describes the influences for the costumes as including 'a vintage picture of two little kids at a carnival wearing giant paper mâché heads as backpacks', Kansai Yamamoto's avant-garde designs for David Bowie, 90s cartoon Aaahh Real Monsters, and 'Cyrus' own love of funny faces, mouths and especially tongues' (Callahan in Brillson 2015). The multiple eye imagery that covers the stage suggests the evil eye motif, with its connotations of malevolence and protection and, critically, the gaze. In its unavoidable presence on stage, the symbolic 'look' is turned back towards the audience. The body, disjointed, monstrous and disruptive in its excess, is a powerful theme of this performance. In the monstrous contortions the 'monstrous feminine' is evoked: 'what it is about women that is shocking, terrifying, horrific, abject' (Creed, 1986, 1). As drag queen and performer Laganja Estranga describes:

Costumed in detached badass body parts by Harouche and BCalla, we embraced how odd and grotesquely gorgeous the human form is. Because body parts are hella weird. And genitals are just that...parts. We are so much more than braces-faces, and eyes as 
hands, and googly-toothed ponchos - a body is just parts, and it's the queen who shines beneath the bullshit (2015).

Thus, Cyrus seems to take the hypervisibility of the woman's body in the heteronormative imaginary of public discourse to its extreme, and in doing so disrupt the regulatory norms of its containment. In her study on 'the explicit body in performance', Rebecca Schneider describes the use of the body 'as the stages across which [performance artists] reenact social drama and traumas which have been attributed cultural differentiation between truth and illusion, reality and dream, fact and fantasy, natural and unnatural, essential and constructed' (1997: 7). In a similar manner, Cyrus reenacts the 'social drama and traumas' of living and representing femininity. The contradictory processes of the 'hyper-sexualised, hyper-feminine meanings of postfeminist media subjectivities' (Jackson \& Vares, 2011: 134) are made excessively visible, and thus, perhaps, unstable.

On a subsequent tour, Cyrus continued and extended the aesthetic of the 2015 VMA performance. As in the VMAs, Cyrus appeared in a variety of costumes, including an outfit she describes as a 'pornicorn': this involved Cyrus, in a rainbow wig and unicorn horn, dressed in silver boots, a sparkly tail and a silver s\&m style outfit of strap and metal rings: revealing, or so it appears, her breasts (Miley Cyrus Videos, 2016). Wearing a large strap on dildo, Cyrus sings the song 'Karen Don't be Sad' (Smiley Miley Inc. 2015). The closing lyrics repeat the instruction, 'don't let them win', and as she sings Cyrus pulls off the dildo to reveal what looks like her naked crotch. Evoking the symbolism of the castration complex, the move connotes what Mulvey's critical work on the male gaze describes as the voyeuristic reveal of the woman's body; in a reversal of this convention, the move is invoked by the woman. As the song finishes, Cyrus tells the crowd: 'now this, this isn't my real pussy and these aren't my real tits'. Cyrus seems to play here with the gendered conventions of visual representation and with the performativity of gender itself. First confronted with the combination of the breasts and the dildo, 
Cyrus evokes tropes of queer performance and drag culture. Believing the dildo to be the drag, its removal promises to reassure us of her 'real' sex. Yet, at the moment it seems her body is fully revealed, this too turns out to be illusionary construct, blocking our voyeuristic gaze and the logic of binary gender. Playing out a version of Butler's drag, Cyrus reminds us of the instability of these signifiers. If we recall the 2013 performance with which this article began, we might find similar strands of playful performativity. Cyrus' exaggerated descent down the stairs, her poses, pouts and twirling of imaginary hair, similarly play out the conventions of femininity in ways that expose 'the imitative structure of gender' (Butler,1990: 137). In this sense, Cyrus seems to perform a kind of drag version of pop femininity. Indeed, in an article for People magazine drag queen and performer in the VMA show Shangela claims Cyrus as a 'drag sister':

She embraced us so much. And not just that - anybody can say 'I love you guys' and watch the show - but Miley knows. She knows our lingo, she knows the moves, she knows our music and she had almost 20 costume changes during her VMA hosting debut. And that's drag (in Maslow, 2015).

In her analysis of queer feminist performer Lois Weaver, Deanna Shoemaker explores 'the idea that a female-marked body can consciously and critically drag "femininity" in performance', and thus 'potentially [problematise] oppositional and heteronormative categories of masculinity and femininity' (2007: 319). As Shangela argues, we might read a similar provocation in Cyrus' performance. Thus, Cyrus's media presence can be understood as continuing a tradition of queer feminist performance, mobilising the body as performative confrontation.

\section{'Miley, what's good?': The racialised limits of Miley Cyrus}

If Cyrus pushes against notions of appropriate sexuality, she also raises questions about who gets to offer such provocations and what the limits of those provocations might be. As Schneider reflects 'the 
explicit body in feminist work interrogates socio-cultural understandings of the appropriate and/or the appropriately transgressive - particularly who gets to mark what (in)appropriate where and who has the right to appropriate what where' (1997: 2). Prior to the 2015 VMA awards, pop singer and performer Nicki Minaj posted a series of tweets in which she challenged the racialised inequality of the music industry: 'If your video celebrates women with very slim bodies, you will be nominated for vid of the year... I'm not always confident. Just tired. Black women influence pop culture so much, but are rarely rewarded for it' (2015). This inspired a public conversation on race and representation that included a Twitter debate with Taylor Swift, who initially challenged Minaj before apologising for misunderstanding her arguments. In an interview not long after, Cyrus was asked to comment on the debate reportedly criticising Minaj's approach, describing it as 'not too polite' (in Coscarelli 2015). The racialised dynamics of Cyrus' own media presence have been summarised by Dodai Stewart as: ‘basically, she, as a rich white woman, is "playing" at being a minority specifically from a lower socio-economic level. Along with the gold grill and some hand gestures, Miley straight-up appropriates the accoutrements associated with certain black people on the fringes of society' (2013). In response to such critiques and the twerking debate Cyrus stated: 'a lot of people who have made those comments are older - they were living in a world that was more defined by colour. Now that isn't black culture-that's just culture in general. That's pop culture; that's the way we dance' (in Gevinson, 2014). Unlike her mobilisation of queer/LGBT politics, this problematic account evokes a post-racial discourse that obscures continued violence and inequality. Furthermore, Cyrus' response to Minaj closes down the possibility of her critique, positioning Minaj in the familiar stereotype of the 'angry black woman' and mobilising the same discourse of appropriate and inappropriate forms of public visibility and intervention that are used against her. Here, it is Cyrus who becomes the good girl and Minaj the inappropriate disruption. In an interview with The New York Times, Minaj articulates the limits of Cyrus' response: 
You're in videos with black men, and you're bringing out black women on your stages, but you don't want to know how black women feel about something that's so important?... If you want to enjoy our culture and our lifestyle, bond with us, dance with us, have fun with us, twerk with us, rap with us, then you should also want to know what affects us, what is bothering us, what we feel is unfair to us (in Grigoriadis, 2015)

Minaj's confrontation of Cyrus as the 2015 VMA awards - in which she ended her acceptance speech for best hip hop video with the statement - 'and now, back to this bitch who had a lot to say about me the other day in the press. Miley, what's good?' - functions as critical rupture. Here, Minaj offers a further provocation; resisting a racialised silencing and intervening in the exclusions of this performative project.

\section{Conclusion: 'I hear what you say and I'm gonna do the opposite of it. Because you're old and you're a man, and I'm young and I'm a girl and I know that's right' (Cyrus in Gevinson 2014).}

There is, as Anita Brady argues, an 'enduring tension that defining female sexual freedom presents for feminist politics' (2016: 430). Such tensions converge in the contentious figure of Miley Cyrus. Following the release of Cyrus' single 'Wrecking Ball' (RCA, 2013), public debate coalesced around a series of open letters to Cyrus initiated by Sinead O'Connor. The music video for 'Wrecking Ball' is, as Cyrus has stated, inspired by O'Connor's 1990 hit 'Nothing Compares 2 U' (Chrysalis); opening with a close up of Cyrus' face - hair shaved at the sides, eyes tearful, singing directly into the camera - Cyrus directly recalls the close up on O'Connor's own face in 'Nothing Compares 2 U's now iconic imagery. Following Cyrus' discussion of this in Rolling Stone magazine (in Eells, 2013) O'Connor challenged the comparison, expressing concern that Cyrus was 'allowing [herself] to be pimped' and 'exploited' by the music business (O’Connor, 2013). As Brady argues, 'part of what is at stake in [Cyrus and O'Connor's] exchanges, and in the media commentary that followed, are determinations of what counts as a feminist action, and who gets to adjudicate on its political veracity' (2016: 432). Further, I 
would argue, at stake in these debates is a sense of the successes and/or failures of feminist struggle. In the context of a long standing fight against media sexism and the precarities of postfeminist representations, the explicit imagery of Cyrus can seem to signify a failed feminist project. Cyrus, describing herself as 'one of the biggest feminists in the world because I tell women to not be scared of anything' (in Butterly, 2013), might be read as troubling embodiment of postfeminist narratives of choice and sexual freedom on (hetero)sexualised terms. Playing close attention to this content, however, reveals a series of more complex provocations in this seeming embrace of the logic of sexualisation. There is a queerness to this content and a provocative evocation of gender and power that denies the heterosexist imperative of postfeminism. Thus, in the explicit confrontations of her performances, we might in fact encounter a productive, if contradictory, resistance to the ordering and regulation that defines young femininity in hetero-patriarchal social worlds. A disruption, rather than a securing, of the postfeminist imperative towards 'the self-surveillance and discipline now normatively required of women' (Gill, 2007). In this sense, we might find in Cyrus a continuity with an existing sensibility of feminist struggle, and the mobilisation of pop cultural platforms that open up feminist possibility rather than signify feminist loss. There are of course limits to the politics of performativity made present here. In particular, the uncomfortable fact of Cyrus' collaborations with Terry Richardson - a photographer accused of multiple counts of sexual harassment and whose work "charmlessly blurs the boundaries of editorial fashion photography and hard core pornography' (Ferreday, 2014: 144) - and the problematic dynamics of race and gender. Certainly, there are multiple forms of racialized privileges and limits at play here, in both Cyrus' media content and the ways in which the threat of sexualisation is constituted as concern. These tensions, however, resonate throughout feminist struggle, and thus might themselves be opened up more productively if we engage with them on these terms; recognising also, the power of Minaj's critique. Cyrus functions then, not as a coherent feminist role model, but as hyper-referential pop performance figure; resisting reductive sense-making, she mobilises a messy convergence of the 
contradictory struggles of young women's lives, bodies and desires. In the excesses of this visual media, there is, as Cyrus suggests, power in the playful performativity of these provocations.

\section{Notes}

i This account is not a comprehensive one, and there are certainly other readings to be made of this figure and other (counter) examples that could be drawn on. My aim here is to offer readings of underexplored elements of this media figure, drawing attention to the disruptive possibilities of her circulation in media cultures.

ii Throughout this article I deliberately use quotations from Cyrus' interviews to explore this discussion. In the context of a debate that often excludes the sense-making of its subjects (young women and girls), and a broader resistance to considering agency, critical awareness and political possibility in a figure such as the young, female pop star, this is an attempt to insist on their significance. This is not, however, to imply that these words offer a direct or 'truthful' account of Cyrus or her intentions, these are of course media(ted) materials, but these mediations are critical ones.

iii The project featured Cyrus releasing a series of 'Backyard sessions', also available on Cyrus' YouTube channel, featuring Cyrus and guests performing a series of covers. The series included performers such as pop/r\&b singer Ariana Grande, rock singer and musician Joan Jett, folk/pop singer Melanie Safka and Laura Jane Grace of punk band Against Me!. Notably, songs included Against Me!'s 'True Trans Soul rebel', 'Androgynous' (first performed by The Replacements and later covered by Jett) and Jett's 'Different'.

\section{Bibliography}

Attwood, Feona and Clarissa Smith (2011) 'Investigating Young People’s Sexual Cultures: An Introduction'. Sex Education, 11(3): 235-242.

Bailey, Reg (2011) Letting Children Be Children: Report of an Independent Review of the Commercialisation and Sexualisation of Childhood. Vol. 8078. The Stationery Office.

Barker, Meg, and Robbie Duschinsky (2012) ‘Sexualisation’s Four Faces: Sexualisation and Gender Stereotyping in the Bailey Review.' Gender and Education 24(3): 303-310.

Blackman, Lisa (2009) 'The Re-Making of Sexual Kinds: Queer Subjects and the Limits of Representation'. Journal of Lesbian Studies. 13 (2): 122-135.

Blue, Morgan Genevieve (2013) 'The Best of Both Worlds?: Youth, gender, and a post-feminist sensibility in Disney's Hannah Montana'. Feminist Media Studies. 13(4): 660-675. 
Brady, Anita (2016) 'Taking time between g-string changes to educate ourselves: Sinéad O’Connor, Miley Cyrus, and celebrity feminism'. Feminist Media Studies. 16(3): 429-444.

Brillson, Leila (2015) 'How to dress Miley Cyrus and 31 drag queens: meet bcalla'. Nylon. 31 Aug, 2015 Butler, Judith (1990) Gender Trouble. London: Routledge.

Butterly, Amelia (2013) 'Miley Cyrus says she's “one of the biggest feminists"'. BBC Newsbeat. 12 Nov, 2013. Available at: http://www.bbc.co.uk/newsbeat/article/24911610/miley-cyrus-says-shes-oneof-the-biggest-feminists (Accessed 1 March, 2017)

Coscarelli, Joe (2015) 'Inside the Making of 'Dead Petz,' Miley Cyrus’s Surprise Album'. The New York Times. 31 Aug, 2015.

Creed, Barbara (1986) 'Horror and the Monstrous-Feminine: An Imaginary Abjection'. Screen. 27(1): 4471.

Cyrus, Miley (2011) 'I'm the bad girl for growing up, I'm the bad girl for living my dreams, No matter what, I'm the bad girl' Twitter [deleted tweet]

De Casparis, Lena (2015) 'Miley Cyrus On Sexuality, The New Frontier’. Elle. 21 Sept, 2015.

Dines, Gail \& Julia Long (2011) 'Moral panic? No. We are resisting the pornification of women'. The Guardian. 1 Dec, 2011.

Dougill, Andy. 2013. Energising development with Jatropha curcas? Biofuel reflections from Mali in @PracticalAction briefing paper[Twitter]. 16 April. Available from: https://twitter.com/AndyDougill [Accessed: 8 September 2013].

Durham, M Gigi (2008) The Lolita Effect: The Media Sexualization of Young Girls and What We Can Do About It. London: Duckworth Overlook.

Duschinsky, Robbie (2012) 'The Emergence of Sexualization as a Social Problem: 1981-2010'. Social Politics. 20(1): 137-156.

Duschinsky, Robbie (2013) 'What Does Sexualisation Mean?’ Feminist Theory 14(3): 255-264. 
Eells, Josh (2013) 'Miley Cyrus on Why She Loves Weed, Went Wild at the VMAs and Much More'. Rolling Stone. 27 Sept, 2013. Available at: http://www.rollingstone.com/music/news/miley-cyruson-why-she-loves-weed-went-wild-at-the-vmas-and-much-more-20130927 (Accessed 1 March 2017)

Epstein, Debbie, Mary Jane Kehily and Emma Renold (2012) 'Culture, policy and the un/marked child: fragments of the sexualisation debates'. Gender and Education. 24(3): 249-254.

Estranja, Laganja (2015) 'Diary Of A Dirty Hippie \#4'. V Magazine. Available at: http://vmagazine.com/article/diary-of-a-dirty-hippie-4/ (accessed 7 Jan 2015)

Ferreday, Debra (2014) 'The Feminine Art of Failure: queering feminist spectatorship'. Quaderns de Psicologia. 16(1): 141-152.

Gaunt, Kyra D. (2015) 'YouTube, Twerking \& You: Context Collapse and the Handheld Co-Presence of Black Girls and Miley Cyrus’. Journal of Popular Music Studies. 27(3): 244-273.

Gevinson, Tavi (2014) 'Not a Girl, Not Yet a Woman: the Two Sides of Miley Cyrus'. Elle. 30 Apr, 2014.

Gill, Rosalind (2007) 'Postfeminist media culture: Elements of a sensibility'. European Journal of Cultural Studies. 10(2): 147-166

Gill, Rosalind (2009) 'Beyond the 'Sexualization of Culture' Thesis: An Intersectional Analysis of 'Sixpacks', 'Midriffs' and 'Hot Lesbians' in Advertising'. Sexualities. 12(2): 137-160.

Gill, Rosalind (2012) 'Media, Empowerment and the "'Sexualization of Culture' Debates'. Sex Roles, 66(11-12): 736-745.

Gill, Rosalind (2012) 'The Sexualisation of Culture?' Social and Personality Psychology Compass 6(7): 483-498.

Gill, Rosalind, and Christina Scharff, eds. (2011) New Femininities: Postfeminism, Neoliberalism, and Subjectivity. London: Palgrave Macmillan. 
Graham, Georgia (2013) 'Miley Cyrus has "far greater" effect than hardcore pornography'. The Telegraph. 29 Oct, 2013.

Griffiths, Kerry (2016) Femininity, Feminism and Recreational Pole Dancing. Oxon: Routledge. Grigoriadis, Vanessa (2015) 'The Passion of Nicki'. The New York Times. 7 Oct, 2015.

Hamad, Hannah and Anthea Taylor (2015) 'Introduction: feminism and contemporary celebrity culture' Celebrity Studies. 6(1): 124-127.

Hann, Michael (2013) ‘Miley Cyrus's new Wrecking Ball video says young women should be sexually available'. The Guardian. 10 Sept, 2013.

Harris, Anita (2004) Future Girl: Young Women in the Twenty-First Century. London: Routledge.

Horeck, Tanya (2014) ‘\#AskThicke: “Blurred Lines,” Rape Culture, and the Feminist Hashtag Takeover’. Feminist Media Studies. 14(6): 1105-1107.

Jackson, Sue \& Sarah Goddard (2015) 'I'd say 14 is too young': Pre-teen girls' negotiations of 'sexualized' media. Continuum. 29(2): 241-252.

Jackson, Sue and Tiina Vares (2011) 'Media 'Sluts': ‘Tween' Girls' Negotiations of Postfeminist Sexual Subjectivities in Popular Culture' in Gill, Rosalind and Christina Scharff, eds. New Femininities: Postfeminism, Neoliberalism, and Subjectivity. London: Palgrave Macmillan. 134-146.

Jackson, Sue, Sarah Goddard and Sophie Cossens (2016) ‘The importance of [not] being Miley: Girls making sense of Miley Cyrus'. European Journal of Cultural Studies. 19(1): 1-18.

Krochmal, Shana Naomi (2015) ‘Exclusive: Miley Cyrus Launches Anti-Homelessness, Pro-LGBT 'Happy Hippie Foundation'. Out. 5 May, 2015.

Levy, Ariel (2005) Female Chauvinist Pigs: Women and the Rise of Raunch Culture. London: Simon and Schuster.

Maslow, Nick (2015) 'Go Inside the VMAs with Miley Cyrus' Dancer, Drag Queen Shangela: 'When We Hit That Final Pose, It Was Epic'. People. Available at: 
http://www.people.com/people/package/article/0,,20946992_20950286,00.html (accessed 9 March 2016)

McCann, Hannah (2015) 'Pantomime Dames: Queer Femininity Versus 'Natural Beauty’ in Snog, Marry, Avoid'. Australian Feminist Studies. 30(85): 238-251.

Miley Cyrus Videos (2016) 'Miley Cyrus and Her Dead Petz LIVE (HD \& HQ Audio) - The Milky Milky Milk Tour'. Available at: https://www.youtube.com/watch?v=tIBaVCvM02c (accessed 6 March 2016)

Minaj, Nicki (2015) 'If your video celebrates women with very slim bodies, you will be nominated for vid of the year...' Twitter. 21 July, 2015. Available at: https://twitter.com/nickiminaj/status/623608271774072832?lang=en-gb (accessed 22 July 2015).

Minaj, Nicki (2015) 'I'm not always confident. Just tired. Black women influence pop culture so much, but are rarely rewarded for it' Twitter. 21 July, 2015. Available at: https://twitter.com/NICKIMINAJ?ref_src=twsrc\%5Egoogle\%7Ctwcamp $\% 5$ Eserp $\% 7 C t w g r \% 5 E a u$ thor (accessed 22 July 2015).

Mohammed, Jameel (2015) 'Where art and commerce clash: thinking through non commercial design with BCalla, 69, and Threeasfour'. Paper. 1 Oct, 2015.

Montgomery, James (2013) 'Exclusive: Miley Cyrus breaks silence over VMA performance'. MTV News. Available at: http://www.mtv.com/news/1713414/miley-cyrus-vma-performance-interview/ (accessed 20 Nov 2015)

Morgan, Maybelle (2015) 'Parents rank Miley Cyrus as the WORST celebrity role model for children... while the Duchess of Cambridge is named the best'. The Daily Mail, MailOnline. Available at: http://www.dailymail.co.uk/femail/article-3209970/Parents-rank-Miley-Cyrus-WORST-celebrityrole-model-children.html (accessed 2 Dec 2015). 
O’Connor, Sinead (2013) 'Open Letter to Miley Cyrus'. Sinead O’Connor.com. Available at: http://www.sineadoconnor.com/2013/10/open-letter-to-miley-cyrus/ (accessed 4 Dec 2013)

Paul, Pamela (2005) Pornified: How Pornography Is Transforming Our Lives, Our Relationships, and Our Families. New York: Holt Paperbacks.

Petrusich, Amanda (2015) 'Free to be Miley’. Paper. 9 June, 2015

Phili, Stelios (2013) 'Robin Thicke on That Banned Video, Collaborating with 2 Chainz and Kendrick Lamar, and His New Film'. GQ. 6 May, 2013.

Poulson-Bryant, Scott (2013) “"Put Some Bass in Your Walk": Notes on Queerness, Hip Hop, and the Spectacle of the Undoable'. Palimpsest: A Journal on Women, Gender, and the Black International. 2(2): 214-225.

Renold, Emma (2008) 'Queering Masculinity: Re-Theorising Contemporary Tomboyism in the Schizoid Space of Innocent/Heterosexualized Young Femininities'. Girlhood Studies. 1(2): 129-151.

Renold, Emma and Jessica Ringrose (2011) ‘Schizoid Subjectivities? Re-theorising Teen Girls' Sexual Cultures in an Era of "Sexualisation"”, Journal of Sociology, 47(4): 389-409.

Schneider, Rebecca (1997) The Explicit Body in Performance. London: Routledge.

Shoemaker, Deanna (2007) 'Pink Tornados and Volcanic Desire: Lois Weaver's Resistant 'Femme(nini)tease' in "Faith and Dancing: Mapping Femininity and Other Natural Disasters"'. Text and Performance Quarterly. 27(4): 317-333.

Steinmetz, Katy (2015) 'Miley Cyrus: 'You Can Just Be Whatever You Want to Be'’. Time. 15 June, 2015.

Stewart, Dodai (2013) 'On Miley Cyrus, Ratchet Culture and Accessorizing With Black People’. Jezebel. Available at: http://jezebel.com/on-miley-cyrus-ratchet-culture-and-accessorizing-with-514381016 (accessed 3 July 2014). 
Tankard Reist, Melinda (2009) Getting Real: Challenging the Sexualisation of Girls. Melbourne: Spinifex Press.

The Happy Hippie Foundation (2015) 'Our work'. The Happy Hippie Foundation. Available at: http://www.happyhippies.org/ (accessed 6 Jan 2016).

The Telegraph (2010) 'David Cameron promises to protect children from 'inappropriate sexualisation'. The Telegraph. 18 Feb, 2010.

Vares, Tiina and Sue Jackson (2015) 'Reading celebrities/narrating selves: ‘tween' girls, Miley Cyrus and the good/bad girl binary'. Celebrity Studies. 6(4): 553-567

Video Music Awards (2013) Television Broadcast. USA: MTV. 25 August 2013.

Video Music Awards (2015) Television Broadcast. USA: MTV. 30 August 2013.

Williams II, Mike L., Pierre Ramon Slaughter, Timothy Thomas, Theron Thomas, Miley Cyrus, Douglas Davis \& Ricky Walters (2013) We Can't Stop. New York: RCA.

\section{Acknowledgements}

This paper emerged out of multiple discussions on Miley Cyrus, pop culture, feminism and femininity with Debra Ferreday, and is deeply indebted to that continued collaboration. Thanks also to Ece Kocabicak for very helpful discussions on Cyrus as a feminist figure. 